\title{
No hay capital hecho sin sangre. Entrevista a Yolanda Colom
}

There is not capital made without blood. Interview with Yolanda Colom

\author{
NATHALIE NARVÁEZ \\ UNIVERSITÉ BRETAGNE OCCIDENTALE-BREST · nathalienarvaez@yahoo.fr
}

DOI: $10.7203 /$ KAM.6.7843

ISSN: 2340-1869

Esta entrevista tuvo lugar en los días seis y siete de julio de 2015 en Guatemala. Nos vimos el primer día en la gran casa de la cultura y editorial Del Pensativo, de estilo colonial, afincada en la hermosa ciudad de Antigua. El segundo día nos encontramos en la Universidad Rafael Landívar, en ciudad de Guatemala, donde la autora había sido invitada a un encuentro con estudiantes de literatura para hablar sobre su testimonio y responder a los interrogantes surgidos tras la lectura de su libro en el seno de este grupo de jóvenes.

La generosidad y simpatía con las que Yolanda Colom relata su vida, su sonrisa y su profunda mirada acompañando sus palabras han hecho de este encuentro un maravilloso momento, pese a la dureza de ciertos de los hechos narrados y de algunas de las etapas de esta experiencia vital. Tristemente, el limo político y social de ayer contra el que decidirían luchar, hoy en día persiste en ser la base de la raigambre de la estructura social. Su voz permanece firme en denunciar tales hechos y su relato es reactualizado por la protagonista como muro de contención, de prevención, voz de alarma contra estos usos y abusos de la fuerza que los ricos, los poderosos, las élites, siguen ejerciendo para mantener su estatus. Como ella misma dice: "No hay capital hecho sin sangre, ni lodo, ni lágrimas ajenas". Ante los mismos retos y necesidades sociales de antes, los ideales y decisión de lucha han de mantenerse también. 
A la pregunta que le hicieron los jóvenes universitarios “¿Qué nos diría a los jóvenes?”, ella respondió: "Estudien, porque el país necesita gente preparada. Hay que estudiar con valores y ética. Sabiendo y conociendo la situación actual. Conociendo las dimensiones de la vida, han de estar preparados para trabajar de forma honrada y capaz. Cualquier cambio social necesita gente preparada.”

Su lucha por cambiar las reglas de un juego que solo favorece a unos pocos se mantiene, su voz es ahora su arma, así como el trabajo de formación cívica y política, y las reuniones y asambleas en las que participa. Ha sido un honor y un placer poder conocerla y hablar con ella. Le agradezco de nuevo todo el tiempo pasado con nosotras.

Nacida el 6 de agosto de 1947, Yolanda Colom es una mujer de casi sesenta y ocho años en el momento en el que se realiza esta entrevista. Su trabajo actual es de editora en Del Pensativo y otras editoriales. Del Pensativo publica libros críticos sobre la realidad centroamericana, especialmente guatemalteca (antropología, política, sociología, etc.) y, ocasionalmente DVDs. Es, a la vez, encargada de la Casa Pensativa (eventos culturales, formativos, políticos; funcionamiento, atención a terceros, etc.). En la villa se ofrecen charlas y lecturas al público. La línea editorial es más bien de izquierdas y feminista: elementos esenciales al buen desarrollo de la actividad de nuestra protagonista. Desde hace tres años ejerce como editora, trabajo que le fue propuesto por Ana María Cofiño, antropóloga y connotada intelectual y activista pro derechos de las mujeres e igualdad de género.

NATHALIE NARVÁEZ. ¿Cómo llegó a la lucha y a vivir su vida de esta manera tan peculiar?

YOLANDA COLOM. Soy hija de una familia capitalina de clase media profesional, sin patrimonio material ni económico, pero con la firme idea de que la educación y el trabajo asalariado era lo que podía sacar adelante a los jóvenes. Cualitativamente me gradué en la década de 1960 en Monte María, un colegio católico donde se cultivaba la conciencia social. Fui educada de forma católica, anticomunista y democráticamente. Por aquel entonces las monjas y curas promovían el trabajo voluntario en las misiones de Huehuetenango. Y respondí al llamado de ayudar. Nos fuimos 8 estudiantes durante un año a esa zona, excluida, marginada, donde un carro entraba una vez a la semana, donde el único contacto con el exterior, con otros habitantes del país, era por telégrafo en código morse. Hice pues mi magisterio en un pueblo Mam. Esta experiencia me hizo reflexionar, siempre me pregunté cómo podía ser que hubiese tanto contraste entre las clases sociales, por qué esas diferencias e injusticias eran posibles. Al llegar ahí, no me alcanzó el conocimiento adquirido hasta entonces para entender lo que estaba viendo y viviendo. Mis herramientas teóricas no podían explicar lo que estaba sucediendo. El curso de ese año me transforma a mí por dentro. Todo ese bagaje que tenía para entender a mi país y para entender mi lugar en mi país y para entender mi deber ciudadano, ahí se me hizo polvo. La formación cristiana que tuve se 
me derrumba al ir a la misión. A los diecinueve años voy a dar un año de mi vida de manera gratuita, al servicio de mi país y lo que vi me desbordó: el reclutamiento militar, la fuerza bruta del ejército, la "agarrada" de niños de 13 a 14 años, hombres casados, etc. Sin médicos, ni enfermeras, ni farmacia, uno se cura a la buena de dios o no se cura. Por los caminos a pie y con mecapal para cargar a la espalda se pagaba a un quetzal (en 1967 era equivalente a un dólar) por cargar 100 libras o más durante ocho o más horas en veredas montañosas. Literalmente el ser humano haciendo de bestia de carga. Y actualmente seguimos igual al respecto. Esto que veía ahí era en todas partes de mi país, y ahí me digo, no, no me explico cómo siendo un país rico podía haber tanta miseria. Así que no era suficiente dar sólo un año de servicio voluntario, como pensaba cuando llegué al pueble. No era coherente hacerme la desentendida ante tan extrema, dolorosa y dura realidad de la mayoría de compatriotas.

NATHALIE NARVÁEZ. ¿Prosiguió su formación? ¿cómo evolucionó su pensamiento después de ese impacto?

Yolanda Colom. Sólo estudié un año y medio en la universidad, en la enseñanza oficial e institucional (1968 y 1969). Al terminar mi año de servicio, en octubre de 1967, viajé de paseo a Europa gracias al apoyo familiar. Había sido invitada por mi tía, dos meses. Allí estuve en España, Francia, Italia y Grecia. Era el París de las minifaldas, las usábamos también en la ciudad de Guatemala, pero lo que fue un descubrimiento es el maquillaje, la desenvoltura, la liberalidad sexual de las jóvenes parisinas de clase media y alta. Eso era lo que contrastaba, al igual que en el campamento scout de Yellowstone en 1965, y me demostraba que las latinas éramos excesivamente pudorosas, temerosas de nuestra desnudez.

En efecto, había experimentado esa diferencia cuando con 16 años acudí a una reunión mundial de muchachas guía de entre 7 y 22 años en Yellowstone. Éramos 10.000 patojas y 11.000 guiadoras. Fue una experiencia muy interesante. Estuve dos meses en total en los E.E.U.U. de América: un mes y medio en el encuentro y cinco semanas en una comunidad judía de mucha plata en Nueva York, una viajando en tren desde Nueva York hasta Seattle con ellas y dos semanas de campamento scout.

Ese viaje significó mucho para mí. Por ejemplo, descubrí la diferencia cultural con respecto a la mirada sobre la desnudez. Si las latinoamericanas le poníamos coco a ello, las norteamericanas y las europeas actuaban con naturalidad al respecto.

El segundo viaje a Europa también fue muy importante en mi evolución. Mi novio se trasladó a vivir a París, becado por la Sorbonne para hacer el doctorado. En un principio se fue solo. Yo empecé a dar clases de artes plásticas y a estudiar en la universidad. Pero al año de haberse ido, mi novio retornó a Guatemala en sus primeras vacaciones con la propuesta de que nos casáramos y volviéramos juntos a Europa. Viajamos pues los dos de vuelta a París. Viajamos de Francia a España, donde pasaríamos el fin 
de año con unos tíos radicados en Madrid. Los compañeros de viaje eran obreros y empleadas domésticas españolas que viajaban para pasar las fiestas en familia. Simpatizamos con ellos.

Visité Suiza, Bélgica, Holanda, España e Italia de mochilera, en $3^{\text {a }}$ clase.

Descubrí en el París de 1969-1970 la versión no oficial, la visión crítica del discurso dominante de las revoluciones latinoamericanas. Salía del ambiente represivo y conservador de Guatemala para conocer la Francia post 68, los exiliados de República Dominicana, de México (perseguidos de Tlatelolco de 1968), de Guatemala, obvio, pero también de otros países africanos, latinoamericanas y asiáticos. Descubrí los grandes escritos marxistas y leninistas, lo que significaba "ser comunista". Pude leer la historia no oficial de Latinoamérica, tuve acceso a libros que nunca antes había podido leer. Escuché una conferencia de Dom Hélder Cámara en la década de los 1960 en París, Obispo de Olinda y Recife, adalid, entonces, de la teología de la liberación en América latina. Leí a Jorge Amado, por ejemplo, o fui a la sede de la UNESCO donde encontré manuscritos de Paulo Freire. Descubrí lo que era ser cura-obrero, conocí al mismo tiempo lo que era el exilio. Yo no conocía esa palabra. Iba abriendo mi visión también, aprendiendo de las situaciones de otros países.

En Francia iba al instituto donde estudiaba mi marido y entraba en los seminarios y conferencias de temas que me parecieran interesantes, y la persona docente competente. Pero no hice carrera universitaria. No me adapté al régimen y ambiente académico, quizás porque no era mi camino para formarme y trabajar. En realidad, mi formación teórica ha sido más bien accidentada, por rachas. Más alternada con la acción, la solución de problemas concretos y la búsqueda de comprensión de los acontecimientos y proceder humanos. Y sigo estudiando. Toda mi vida, leeré y estudiaré por mi cuenta o con otros, para comprender la realidad de mi país o partes de esa realidad.

Pero sí, ese año, con todas las lecturas, todo este estudio, ese año me modifica la percepción.

A mi regreso a Guatemala en 1971 empecé a considerar la posibilidad de formar parte de la lucha armada. Sin embargo, la victoria de Allende en Chile representó la posibilidad que tenía el pueblo de llegar al poder por las urnas y no por las armas y me hizo reflexionar. Con mi pareja queríamos ir a ver cómo se organizaban en ese país del cono sur. Nos surgió la ilusión de que podía ser pacífico el cambio.

NATHALIE NARVÁEZ. ¿Qué libros le ayudaron en la reflexión? ¿Qué lecturas aconsejaría?

YOLANDA COLOM. Las lecturas clave para mí, de adolescente, fueron las novelas latinoamericanas de tipo social, sobretodo la Trilogía bananera de Miguel Ángel Asturias (1899-1974) aunque las leí

\footnotetext{
${ }^{1}$ La trilogía bananera se compone de Viento fuerte (1950), El papa verde (1954), y Los ojos de los enterrados (1960). Estas tres novelas recrean ficticiamente la vida de los indígenas guatemaltecos explotados por el control extranjero sobre la industria bananera en Guatemala.
} 
todas de él. Pedro Páramo (1955) del escritor mexicano Juan Rulfo (1917-1986) y El mundo es ancho y ajeno (1941), novela del peruano Ciro Alegría (1909-1967), así como algunos clásicos rusos. Los que me marcaron en mi conciencia social, "así son las cosas en nuestros países, ¿verdad?”, me dije, fueron esos. Pero también leí a Hemingway (1899-1961) Por quién doblan las campanas (1940), su novela sobre la Guerra civil española y a Steinbeck (1902-1968). En Europa me concentro sólo en leer sobre América Latina, sobre Guatemala y obviamente lo prohibido, el marxismo-leninismo. En Francia me dedico a estudiar los clásicos: Marx y Engels, Rosa Luxemburgo, Lenin... Estoy en Europa cuando tienen lugar los procesos de independencia africanos: Amílcar Cabral, Samir Amin, Frantz Fanon... He de decir que me interesé también por la historia sobre las luchas y guerras de emancipación de los pueblos a lo largo de la vida humana. Lo que yo busco es ver ¿cómo a lo largo de la historia los de abajo lucharon contra la injusticia, contra el poder? Leí al respecto la lucha de Espartaco, y Los bienes terrenales del hombre (1936) de Leo Huberman (1903-1968). Así como la unificación de Italia y la defensa de España de las tropas napoleónicas. También aconsejaría la lectura de los libros de Howard Fast (1914-2003) como Mis gloriosos hermanos donde narra la revuelta de los Macabeos de 167 a. C. contra el Imperio Seléucida. Evidentemente leí todo lo que caía entre mis manos sobre Viet Nam en mi época en París (en la década de 1960).

NATHALIE NARVÁEZ. Usted ha sentido un gran interés por formar y acompañar a las personas, por comprender los procesos de aprendizaje. En su testimonio relata una de las misiones que se le encomendaron: el diseño de "un método de alfabetización que pudiera ser empleado en la montaña. El analfabetismo campeaba de la mano con la miseria; pero el deseo de superación era generalizado y urgente la necesidad de elevar el nivel cultural de nuestros miembros y bases." "Elaboró pues un método inspirado en los postulados de Antón Makárenko, pedagogo soviético de principios del siglo XX, y de Paulo Freire, educador brasileño comprometido con la emancipación de los sectores populares.

YoLANDA COLOM. Mi preocupación por la alfabetización y el autoaprendizaje me llevó a leer a Paulo Freire (1921-1997) y a Iván Illich (1926-2002). Yo era una mujer joven, pero inquieta. Acudí a

\footnotetext{
2 Yolanda Colom, Mujeres en la alborada: guerrilla y participación femenina en Guatemala 1973 - 1978; testimonio, 3a ed, Antigua Guatemala, Ed. del Pensativo, 2007, 327 p., (« Colección Nuestra Palabra»), p. 25.
} 
cursos del CIDOC ${ }^{3}$ en Cuernavaca en tres ocasiones. No me pregunten cómo supe de ello, no sé cómo llegué allí. La primera fue a finales de 1968, con 20 años, donde realicé un curso de un mes. Lo primero que me llamó la atención allí fueron documentos del movimiento revolucionario guatemalteco. Recibí un curso con D. Sergio Méndez Arceo, el famoso arzobispo rojo de Cuernavaca, acusado de comunista. Un hombre cultísimo, un hombrón mexicano, que ya en aquel tiempo daba esas misas latinoamericanas que eran un "deschongue" y unos sermones que se pasaba helando por delante a los gringos, al guerrerismo, a la democracia cristiana. Otro que nos dio curso fue Hugo Blanco, dirigente de las guerrillas peruanas. Había gente cercana al sacerdote colombiano Camilo Torres Restrepo ${ }^{4}$. Tomé clases con el abogado Francisco Julião, uno de los autores intelectuales de la Reforma Agraria brasileña, ese curso me marcó. Éramos poquitos, quizás quince por clase, y de todas partes de América. Daban cursos cortos que más eran como pláticas, como debate, como pensar en voz alta.

Por esos tiempos no tenía mucho dinero, contaba con un dólar al día, para todo: alojamiento, comida, transporte. Así que comía una vez al día con 50 centavos, andaba dos veces al día los $4 \mathrm{~km}$ de ida y vuelta para ir al albergue que costaba un dólar. El cura que llevaba el albergue era francés, François de L'Épinay, así que hablé con él, le dije que era guatemalteca y que no tenía más que 50 centavos para pagar el alojamiento pues lo otro lo necesitaba para comer, y él aceptó. Los demás estudiantes eran canadienses y gringos que venían a estudiar español. Para mí que todos fumaban marihuana, a los gringos les tenía pavor, por hippies, y yo era seria, seria, seria, en todo, era muy formalita. Me tocó en un dormitorio con otras gringas, pero vi que no pasaba nada, que no había marihuana, que cada una iba por su lado, nadie molestaba a nadie. Entonces, comprendí mis prejuicios. Después haría dos cursos más, a los 21 y a los 24 años. Allí recuerdo que conocí una delegación de diez chilenos de todas las corrientes de la Unidad Popular, ellos me invitaron a Chile, yo les dije que no tenía “pisto” (dinero) para viajar, “por

${ }^{3}$ El Centro Intercultural de Documentación fue la continuación del Centro de Formación Intercultural (CIF) fundado por un ex jesuita alemán Iván Illich en la década de los 1950 en la Universidad Fordham de Nueva York. Se impartían dos veces al año seminarios intensivos para capacitar a los misioneros norteamericanos para hablar español pero también y sobretodo para entender y respetar las culturas de los países latinoamericanos propiciando un diálogo intercultural entre semejantes. El CIDOC fue fundado con la colaboración de su esposa, Valentina Borremans, Feodora Stancioff y Gerry Morris entre otros. En ese lugar no sólo se enseñaba español, sino que se discutía además, sobre la misión que la Iglesia estaba llevando a cabo en Latinoamérica. A Illich le parecía evidente que la alianza entre la Iglesia y el naciente culto al desarrollo era una trampa. En 1966 con el CIDOC se abrió un controversial espacio de reflexión, en el cual se realizaban intensas discusiones respecto a Latinoamérica y el desarrollo, con intelectuales como Paul Goodman, Erich Fromm, Peter Berger, Paulo Freire, Sergio Méndez Arceo y otras innumerables y destacadísimas personalidades de los cinco continentes. De las discusiones que se llevaron a cabo allí surgieron los Cuadernos de CIDOC, pequeños volúmenes, impresos y encuadernados internamente. Con inaudita velocidad e independencia, para la tecnología editorial de la época. El CIDOC se mantuvo hasta 1976, cuando Iván Illich decidió, voluntariamente, cerrarlo. CIDOC funcionó exactamente un decenio. Valentina era miembro del directorio de una revista francesa llamada Africasí.

${ }^{4}$ Camilo Torres Restrepo fue un sacerdote católico colombiano, pionero de la Teología de la Liberación, cofundador de la primera facultad de Sociología de Colombia y miembro del grupo guerrillero Ejército de Liberación Nacional (ELN). 
alojamiento no te preocupés y si querés nosotros te buscamos trabajo de obrera”. También coincidió esa vez que asistí a un seminario en Cuernavaca, con Zezita, una brasileña un poco mayor que yo, asistente de Dom Hélder Cámara, Arzobispo de Olinda y Recife, Pernambuco (nordeste brasileño). Ella mi invitó a pasarme a su dormitorio, donde estaba sola. Un día que estaba en el albergue, me avisan que tengo una llamada de teléfono de Brasil, pero yo no conocía a nadie en Brasil, pensaba que era un error. Pero no lo era. La llamada era par mí, así que me encontré hablando con Dom Hélder Cámara. Me invitaba a que fuese a conocer sus proyectos en Recife y me da sus contactos.

Así es cómo prosigo mi actividad, el estímulo intelectual seguirá vigente y acompañándome el resto del tiempo.

Nathalie NARVÁEz. Después de su estancia en Europa, al volver a América, ¿se instalan en Guatemala?

YOLANDA COLOM. Mi esposo y yo decidimos ir a ver cómo se organiza el gobierno de Allende para aprender. Viajamos a Chile en 1972. Nos fuimos con pasaje de ida y vuelta. La aerolínea tenía dos alternativas para de retorno a Guatemala, desde Chile, por el mismo precio. Así que tomamos la ruta de Argentina, Brasil y Colombia, donde teníamos amigos.

Estuvimos con mi esposo cuatro meses en Chile, donde trabajamos en una fábrica de muebles finos socializada y donde daban dos comidas al día. Allí nos permitieron asistir a las reuniones del sindicato que dirigía la fábrica. No teníamos ni voz ni voto, naturalmente, pero sólo de escuchar aprendimos muchísimo.

Asistíamos a cursos libres de Ariel Dorfman (1942-) y Armand Mattelart (1936-) ${ }^{5}$. Queríamos aprender, comprender, cómo se desenvolvía el gobierno socialista tras acceder al poder pacíficamente. Tras esos meses, viajamos a Argentina, donde fuimos a ver a una pareja de viejos anarquistas argentinos, Cecilia y Alfredo Seoane, que habíamos conocido en Italia, cuando viajaron seis meses en microbús en Europa. Estos argentinos eran jóvenes en realidad, la juventud no tiene nada que ver con la edad. Estuvimos con ellos quince días. También visitamos al padre Fulgencio Rojas, viejo conocido de los años

\footnotetext{
${ }^{5}$ Ariel Dorfman es escritor, ha sido profesor de literatura iberoamericana en las universidades de Chile, Ámsterdam, La Sorbona, Berkeley y Maryland, así como profesor de estudios latinoamericanos a partir de 1985 en la universidad de Duke. Armand Mattellart es un sociólogo y demógrafo belga que trabajó largos años en la universidad católica de Chile, donde fundó en los sesenta el grupo de investigación "Centro de Estudios de la Realidad Nacional” (CEREN), junto a Michèle Mattelart y Mabel Piccini. Fue experto de la Comisión nombrada por el Vaticano sobre las políticas de control de natalidad. Trabajó también para las Naciones Unidas como experto en desarrollo social. Terminó su carrera de profesor catedrático en Ciencias de la Información y de la Comunicación en la Universidad de París VIII. Los dos escribieron en 1971 el famoso ensayo Para leer al pato Donald. Comunicación de masas y colonialismo donde de-construyen los mecanismos de difusión de la ideología dominante aplicados a la proyección del imaginario de Disney en el mercado latinoamericano.
} 
en Europa, en Córdoba. Era párroco en un barrio popular. Poco tiempo después, lo desapareció la dictadura militar.

Tras Argentina partimos rumbo a Brasil. Aterrizamos en Río y, tras tres días de viaje en autobús, llegamos a Recife. La terminal era paupérrima, para buses de tercera clase. Lodo, oscuridad, galera rústica y la lluvia caía a cántaros.

Todo el viaje fue para nosotros un proceso de formación, pero en Brasil, es donde yo siento una toma de conciencia muy grande y donde decido romper con el mundo cristiano católico.

El encuentro con Dom Hélder Cámara me abrió los ojos. Este arzobispo vivía en una pequeña parroquia popular donde algunos habían pintado en una pared "Comunista, vete de Brasil o ámalo”. Él dormía en un camastro que acompañaba una mesita. Un inodoro y una regadera completaban su dormitorio. Junto a la habitación, había una congregación chiquitita donde se podía comer. Ese era todo su hogar. El palacio arzobispal servía de Centro de Alfabetización y capacitación de oficios; las otras propiedades del arzobispo se habían vendido para poder financiar ciertos proyectos.

El primer proyecto de Dom Hélder Cámara fue un programa con mujeres prostitutas. Organizaba pláticas con ellas: ¿a qué aspiran para ellas?, ¿para sus hijos?, ¿maridos?, etc. Se preocupaba por estas personas, las acompañaba, las ayudaba a tener vidas mejores. 
Visitamos también una explotación de caña de azúcar en Pernambuco que él había comprado ${ }^{6}$. Esta hacienda cañesca funcionaba sin patrón, los sueldos habían aumentado para los trabajadores y aún así seguía siendo competitiva. Habían fundado incluso una Casa Cultural en el seno de la hacienda. Éstos y otros ejemplos, así como el comportamiento diario, la atención al otro que prestaba el arzobispo, hacen de él una persona inconmensurable. Recuerdo que por mi cumpleaños me regaló una torta, una camisita ¡y un bañador! Era un detallista. A pesar de vivir sin nada, conseguía para los demás. Su forma de vivir, de trabajar, me hizo tomar conciencia de la distancia entre lo que proclaman los católicos y su hacer. Él nunca aceptó el cardenalato. Yo por aquel entonces estoy muy confusa y empiezo a sentir que me alejo de la religión.

Nuestra última escala fue en Colombia, donde conocimos a varios discípulos del padre Camilo Torres y allí nos enteramos del golpe de Estado en Chile (1973). La noticia nos conmovió, así que regresamos a Guatemala, decididos a integrar la lucha armada.

\footnotetext{
${ }^{6}$ No es él en persona, sino la Operación Esperanza. A raíz de una fuerte crecida del río Capibaribe, en los 1960, en la región de Recife, surge un fuerte movimiento de solidaridad en el que instituciones públicas, asociaciones, empresas y religiosos varios se encuentran reunidos por una causa común. Dom Hélder Cámara aprovecha este impulso y quiere llevarlo más lejos, la lucha contra la miseria y el subdesarrollo ha de perennizarse en el tiempo. Es así como nace la Operación Esperanza. Ésta se ocupa de manera permanente de quince sectores poblados por más de 100.000 de habitantes, les abrirá la conciencia en cuanto a sus derechos y acompañará la organización de consejos de habitantes, comisiones y grupos de vecinos, embriones de organizaciones populares. Se ocupará también de campañas de vacunas, de lucha contra la verminosis, del mantenimiento de las calles, de la electricidad, del alcantarillado, de las tarifas del autobús, de los convenios con escuelas, del servicio social, etc. A partir de los años 1970 la Operación Esperanza invierte los dones y la financiación europea y norteamericana en la compra de dominios agrícolas que serían destinados a sistemas de explotación comunales o de pequeña propiedad.
} 